\title{
Central Coherence on Prosody and Content in Children with Cochlear Implant by Age Using Stimulus-Discrimination Program
}

\author{
Gwee Nam Park', Wha Soo Kim², Sook Ja Bae', Yeong Ran Seo' \\ ${ }^{1}$ KyeongShin Aural Rehabilitation Center, Daegu, Korea \\ ${ }^{2}$ Department of Speech Pathology, Daegu University, Daegu, Korea \\ ${ }^{3}$ Daegu Dongbu Office Of Education, Daegu, Korea
}

\author{
Stimulus-Discrimination Program을 통해 본 연령에 따른 인공와우 착용 아동의 \\ 운율과 내용에 대한 중앙통합능력 \\ 박귀남 ${ }^{1} \cdot$ 김화수 ${ }^{2} \cdot$ 배숙자 $^{3} \cdot$ 서영란 $^{\prime}$ \\ 경신청각언어연구소 ${ }^{1}$, 대구대학교 언어치료학과 ${ }^{2}$, 대구광역시 동부교육지원청 ${ }^{3}$
}

\begin{abstract}
Purpose: The purpose of this study was to investigate central coherence and auditory perception ability in children with cochlear implant by age. Methods: The S-D program designed as a computer game was employed to present auditory tasks comprised of recombinations of the prosody and content to 40 cochlear implant (CI) children and 45 normal hearing (NH) children. Results: The findings showed that $\mathrm{Cl}$ have shown similar performance on most of test (Stimulus, Prosody, Content) to NH. The Central coherence Test performance of $\mathrm{Cl}$ revealed that their first appearance of central coherence was far behind. Above all, $\mathrm{Cl}$ aged 5 to 11 showed little preference (weak central coherence) for prosody or content, whereas controls have shown a clear preference for content over prosody. In conclusion, the results of present study suggest that cochlear implant children's difficulties in communication by prosody and content seem to be linked to weakness in central coherence, which are due to distortion of parallel stimulation in cochlear implant. In this regard, it seems necessary to develop technological aspects of cochlear implant. Conclusion: The present study recommends both a well-timed auditory training and using cochlear implant in order to improve the central coherence of hearing impaired children.
\end{abstract}

Key Words: Cochlear implant, Prosody, Content, Central coherence, Stimulus-Discrimination program.

Received: September 23, 2015 / Revised: December 18, 2015 / Accepted: December 28, 2015

Correspondence: Yeong Ran Seo, KyeongShin Aural Rehabilitation Center, 54 Namsan-ro 1-gil, Jung-gu, Daegu 41977, Korea

Tel: +82-53-256-3861 / Fax: +82-53-256-3885 / E-mail: ks650518@nate.com

\section{INTRODUCTION}

의학과 과학 기술의 발달에 힘입어 1990년대 후반부터 인공 와우 이식이 보편화되면서 청각장애 아동의 언어 발달에 획기 적인 진보를 이루어 왔다. 고도 난청인의 손상된 청각 세포의 기능을 대신하는 인공와우는 언어적인 요소뿐만 아니라 비언 어적인 기능에까지 청능 훈련의 가능성을 넓혀주었다. 비언어 적인 요소 중 운율(prosody)은 초분절적인 요소로 대화에 있 어서 내용(content)에 화자의 전달 의도를 담는다. 언어의 발달 을 지배하는 규칙으로는 음운론, 형태론, 구문론, 의미론, 화용
론의 5 가지 구성요소로 정의되는데(미국언어청각협회 American Speech-Language-Hearing Association: ASHA, 1993), 운율을 이해하는 것은 이러한 언어 요소의 발달과 원활한 의 사소통을 위해 필수적인 능력이다. 연령에 따라 별다른 노력 없 이도 자연스럽게 언어 발달을 이루어 가는 건청아동과 다르게 청각장애 아동은 듣기 능력의 결함으로 운율의 변별 및 이해에 어려움을 가진다. 청각장애 아동이 가진 이러한 운율 획득의 부족은 언어적 사고에 있어서 통합적인 변질을 가져온다(Lee $\&$ Seok, 2004). 이로 인해 은유, 풍자 및 농담 등 반언어적인 표 현(semi-language expressions)을 이해하기 어려워 원활한 의 
사소통에 이르지 못하게 된다.

2005년부터 인공와우 수술비용의 건강보험 수혜가 시작되고 기기의 발전, 조기 이식이 급증하면서 인공와우 착용 아동의 언어 능력이 향상되었다는 연구 결과가 보고되어 왔다(Govaerts et al., 2002; Huh, 2010; Lanson et al., 2007; Lenarz et al., 1999; May-Mederake et al., 2010; Robinson, 1998; Välimaa et al., 2002). 한편 인공와우 착용 아동의 운율에 대한 연 구는 운율 프로그램을 적용한 중재 연구(Lee \& Seok, 2004; $\mathrm{Seo}, 2010)$ 와 인공와우 아동의 운율 특성에 대한 연구(Beak, 2010; Yang, 2013)로 한정되어 있다. 효율적인 의사소통에는 언 어 이외에 비언어적 표현에도 주의를 기울여 상대의 의도와 정 서를 이해하는 화용적 영역까지 포함되는데 인공와우 착용 아 동을 대상으로 이러한 통합적인 언어 능력에 대한 연구는 부족 한 실정이다.

중앙통합능력(Central Coherence Theory)은 인지 체계의 특성을 설명하는 주된 이론으로, 여러 다른 수준의 정보를 통 합하는 정상적 정보처리의 과정으로써 부분적인 특징보다 전 체적인 의미나 맥락을 구성하려고 하는 기능이다(Frith, 1989). 중앙통합능력은 의미를 이해하는 데에 우선순위를 두고 개념 적인 관련성을 인지하여 효율적으로 정보를 처리하도록 돕는 다. 즉 언어에 있어서 중앙통합능력이란 문장의 의미 파악과 함 께 전체적인 맥락 정보와 개념적 연결고리를 구성하여 화용적 인 언어 이해와 더불어 전체적인 주제를 파악하여 추론하는 능 력으로 볼 수 있다. 이러한 중앙통합능력은 자폐장애, 지적장애 등에서 보이는 독특한 인지 특성을 설명하는 보편적인 이론이 다(Bernardino et al., 2012; Happé \& Frith, 2006).

이와 같이 중앙통합능력으로 인지 특성을 규명하려는 선행 연구에 청각장애를 대상으로 한 경우는 거의 없다. 그 주된 이 유는 약한 중앙통합능력으로 설명되는 인지적 특성이 일반적 으로 지적 능력이 부족한 대상 집단에서 보이는 주된 양상이기 때문이었다. 청각장애는 선천적 또는 후천적으로 청력이 결여되 어 청각적 피드백의 부족으로 초래되는 언어 기능의 결함을 갖 지만 일반적으로 지적장애를 수반하지 않는다. 또한 최근 청각 장애 아동도 인공와우 수술로 청력역치의 개선이 이루어져 말 소리 듣기에 향상된 결과들을 나타내고 있다(Huh et al., 2007).

한편 운율과 내용이 결합된 선행연구들을 살펴보면 생활연 령 4세인 일반아동은 언어발달 특성에 따라 운율보다 내용에 우선순위를 두고 효율적으로 선택하는 중앙통합능력을 발휘하 지만 언어 기능이 결여된 대조집단에서는 운율과 내용 중 어느 한 요소를 우선적으로 선택하는 결과를 보여주지 않았다 (Brooks \& Ploog, 2013; Park \& Kim, 2014; Ploog et al., 2009). 약한 중앙통합능력은 언어 및 비언어적인 요소에 대한 화용적 인 이해를 저해하여 효율적인 의사소통을 방해하는 원인으로
설명될 수 있다. 최근의 연구 결과에 따르면 청각장애 아동은 인 공와우 수술 후에 최적의 매핑이 이루어진 기기를 착용한 보정청 력 상태에서도 26 40 dB HL의 경도 난청을 가진다(Jang, 2008). 또 인공와우 시스템의 기술적인 제한으로 비언어적인 요소의 처리가 열악하고 왜곡되는 현상도 꾸준히 보고되고 있다(Jin, 2006; Lee \& Choi, 2011). 그렇다면 청각장애 아동이 가진 언 어적 장애가 중앙통합능력과는 어떠한 상관관계가 있으며, 인 공와우 착용으로 중앙통합능력에 어떠한 변화를 가져오는지에 대한 신뢰성 있는 연구가 이어진다면, 청각장애 아동의 언어 중 재에 임상적, 학문적으로 유효한 기반이 되리라 기대한다.

본 연구는 자극-인지 프로그램으로 고안된 Stimulus-Discrimination program(S-D program)을 활용하여 운율 및 내 용이 조합된 자극을 제시하였을 때 인공와우 착용 아동의 청 각 인지 특성을 알아보고 연령에 따라 중앙통합능력이 어떻게 변화하는지 조사하여 청각장애에 있어 중앙통합능력 연구의 기초적인 자료를 제시하는 데에 의의를 두었다.

본 논문에서 연구 문제는 다음과 같다.

첫째, 운율과 내용이 조합된 자극(민기는 밥을 먹어요(-) vs. 달 래는 손을 들어요(*))을 제시하였을 때, 인공와우 착용 아동과 건 청아동은 집단과 연령에서 자극 인지 능력에 차이를 보이는가?

둘째, 인공와우 착용 아동과 건청아동은 집단과 연령에서 운 율 및 내용의 인지 능력에 차이를 보이는가?

셋째, 인공와우 착용 아동과 건청아동은 운율 및 내용선호 도를 통해 볼 때 집단과 연령에서 중앙통합능력에 차이를 보이 는가?

\section{MATERIALS AND METHODS}

\section{연구대상}

본 연구는 인공와우 착용 아동 40 명과 건청아동 45 명으로 구성된 총 85 명의 아동들을 대상으로 진행하였다. 인공와우 아 동은 5세, 7세, 9세, 11세, 13세, 15세, 17세, 19세의 생활연령별 로 각각 5명씩 구성되었고 대조집단인 건청아동도 인공와우 아 동과 생활연령 및 대상자수를 일치시켰다. 다만, 3 세 집단의 경 우 인공와우 아동은 실제 대상자가 없고 실험 과제 수행에 난이 도상 어려움이 있어 제외되고 건청아동만 연구에 포함되었다.

\section{인공와우 착용 아동}

인공와우 착용 아동은 대구광역시에 소재한 사설치료기관 에서 청력 및 언어치료를 받고 있는 아동 중 와우 기형이 없으 며 시술 전 청력은 양이 $90 \mathrm{~dB}$ 이상, 인공와우 착용기간이 최 소 3년에서 최대 12년, 재활기간 만 3년 이상인 아동으로 선정 하였고, 인공와우의 종류는 Cochlear사(28명), MedEL사(10명), 
$\mathrm{AB}$ 사(2명)로 구성되었다. S-D program 적용 직전에 실시한 순음청력검사상 500/1,000/2,000 Hz에서 와우 착용 후 평균청 력이 $35 \mathrm{~dB}$ 미만이고, REVT 및 $\mathrm{PRES}$ 검사 결과 수용언어 4 세 이상으로 교사와 부모로부터 지적능력, 인지, 신체적으로 수 반되는 장애가 없는 아동으로 선정하였다.

\section{건청아동}

건청아동은 인공와우 아동과 생활연령이 일치된 아동으로 교사와 부모에 의해 지적능력, 인지, 신체적인 장애가 없는 아동 으로 선정하였다.

\section{연구방법}

인공와우 착용 아동의 연령에 따른 운율 및 내용에 대한 중 앙통합능력을 알아보기 위한 본 연구는 실험 과제 선정, S-D program 제작, 실험 단계로 구성되었다. S-D program의 제작 및 구성은 Park \& Kim(2014)의 자료를 재인용, 보완하였다.

\section{실험 과제 선정}

청각 과제로 운율과 내용이 결합된 문장을 선정하였다. 운율 은 “열정적인 운율;)"과 “뾰로통한 운율:)"을 선정하여 대조시 켰다. 기쁨과 슬픔은 음도 차이가 뚜렷이 구분이 되는 보편적 인 기본 정서이므로 본 연구를 위해 두 정서를 사용하였다 (Grossman et al., 2010; Park \& Park, 2007; Scherer, 1986). 내용은 아동이 운율을 이해하는 데 어려움이 없도록 한국어 기본문형 중 하나인 〈주어 + 목적어 + 서술어〉의 짧은 3어절로
구성된 두 문장(민기는 밥을 먹어요 vs. 달래는 손을 들어요)을 선정하였다. 그리고 두 개의 운율적 특성과 두 개의 내용을 서 로 조합하여 Table 1 과 같이 네 개의 문장을 완성하였다.

운율과 내용을 조합한 네 개의 청각 자극은 Grossman et al.(2010), Park \& Park(2007), 그리고 Scherer(1986)의 운율에 대한 음향학적 기준에 따라 여자 성우 1 명의 목소리를 사용하 여 녹음하였다. 열정적인 두 문장은 기본 주파수가 높고 넓은 범위에 있고(600 2,500 Hz) 음도는 높거나 낮은 역동적인 범위 에 문장의 끝은 음도가 떨어져 있다. 반대로 뾰로통한 두 문장 은 낮고 좁은 기본 주파수에 청각 스펙트럼이 비교적 평평한 형 태를 보이고(200 1,500 Hz) 문장의 끝에서 음도 변화가 크다 (Figure 1). 청각 자극 문장은 Praat software(v.5.0.38; Phonetic Sciences, University of Amsterdam, Amsterdam, the Netherlands)를 사용하여 스테레오 방식으로 녹음하여 제작하였다. Praat으로 완성된 청각 자극은 본 연구를 위해 제작한 $\mathrm{S}-\mathrm{D}$ program에 내장하여 방음실에서 연구자의 휴대용 컴퓨터의 스

Table 1. Auditory stimulus consisting of recombinations in the prosodic and content feature

\begin{tabular}{|c|c|c|c|}
\hline Prosody & Content & Stimulus $(\mathrm{P} \times \mathrm{C})$ & \\
\hline Enthusiastic (:) & $\begin{array}{l}\text { Min-gi-neun ba- } \\
\text { beul meo-geo-yo }\end{array}$ & $\begin{array}{l}\text { Min-gi-neun ba-beul } \\
\text { meo-geo-yo (:) }\end{array}$ & $\mathrm{S}+$ \\
\hline Grouchy : & & $\begin{array}{l}\text { Min-gi-neun ba-beul } \\
\text { meo-geo-yo }:)\end{array}$ & S1 \\
\hline Enthusiastic (:) & $\begin{array}{l}\text { Dal-lae-neun so- } \\
\text { neul deu-reo-yo }\end{array}$ & $\begin{array}{l}\text { Dal-lae-neun so-neul } \\
\text { deu-reo-yo (;) }\end{array}$ & S2 \\
\hline Grouchy $:$ & & $\begin{array}{l}\text { Dal-lae-neun so-neul } \\
\text { deu-reo-yo }:\end{array}$ & S- \\
\hline
\end{tabular}

Figure 1. The acoustic spectrum with the fundamental frequency.

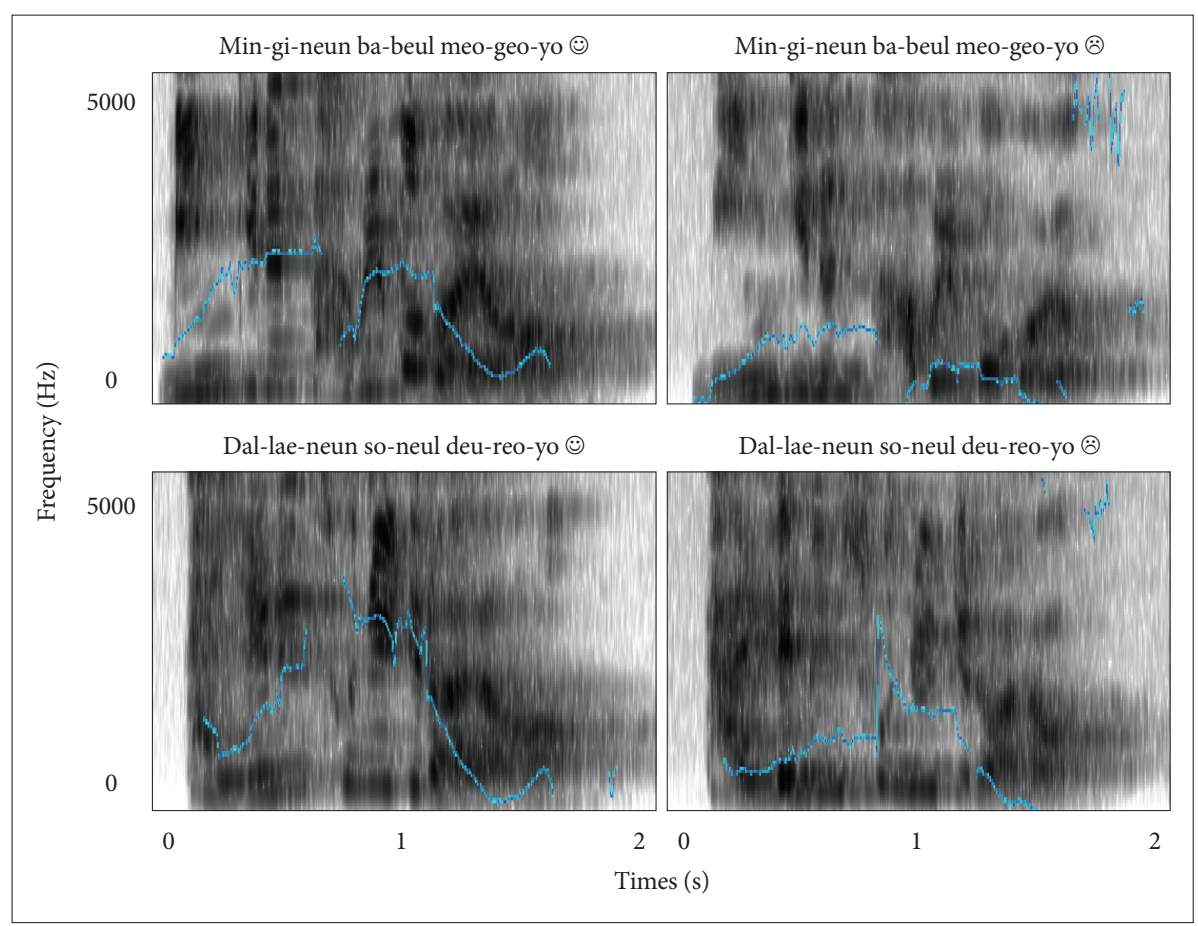


피커를 통해 제시하였으며, 대상자가 가장 잘 들린다고 하는 소 리의 크기(60 dB HL)로 실험을 실시하였다.

\section{S-D program 제작}

S-D program은 선행연구인 Brooks \& Ploog(2013), Ploog et al.(2009)의 연구를 참고하여 한국어로 고안하여 개발하였다.

S-D program은 Adobe Flash Player(v.12; Adobe Systems Inc., San Jose, CA, USA)로 제작되었고 곰플레이어(GOM Player)에서 재생된다. 앞서 Praat으로 완성된 청각 자극은 36세트 로 구성된 테스트로 재생되고, 청각 자극과 함께 컴퓨터 화면 에 캐릭터 그림이 제시된다. 제시되는 그림은 아동들이 좋아하 는 캐릭터 이미지를 PhotoScape(v.3.6.5, Adobe Systems Inc.) 로 편집하여 동영상 파일(gif)로 완성한 것이다.

\section{실험 단계}

본 연구를 위한 실험 절차는 대상자가 청각 과제를 듣고 제 시되는 두 문장 중 하나를 선택하는 컴퓨터 게임 방식으로 설 계되었다. S-D program은 테스트 36세트로 구성되어 있다. 연 구자는 휴대용 노트북 컴퓨터에 탑재된 S-D program을 실행 하고, 본 테스트에 들어가기에 앞서 대상자에게 시범으로 게임 방법을 설명하며 제시되는 두 문장 중 하나(S+)를 마우스로 고 르도록 훈련시켰다.

본 실험에서 대상자가 한 과제를 마치면 일정 시간(2초)이 경 과한 후 다음 과제로 전환되고, 과제의 수행성과는 컴퓨터에
자동으로 저장되었다.

S-D program의 진행 화면은 Figure 2와 같다.

Figure 3은 본 연구에서 활용한 S-D program의 각 실험 단

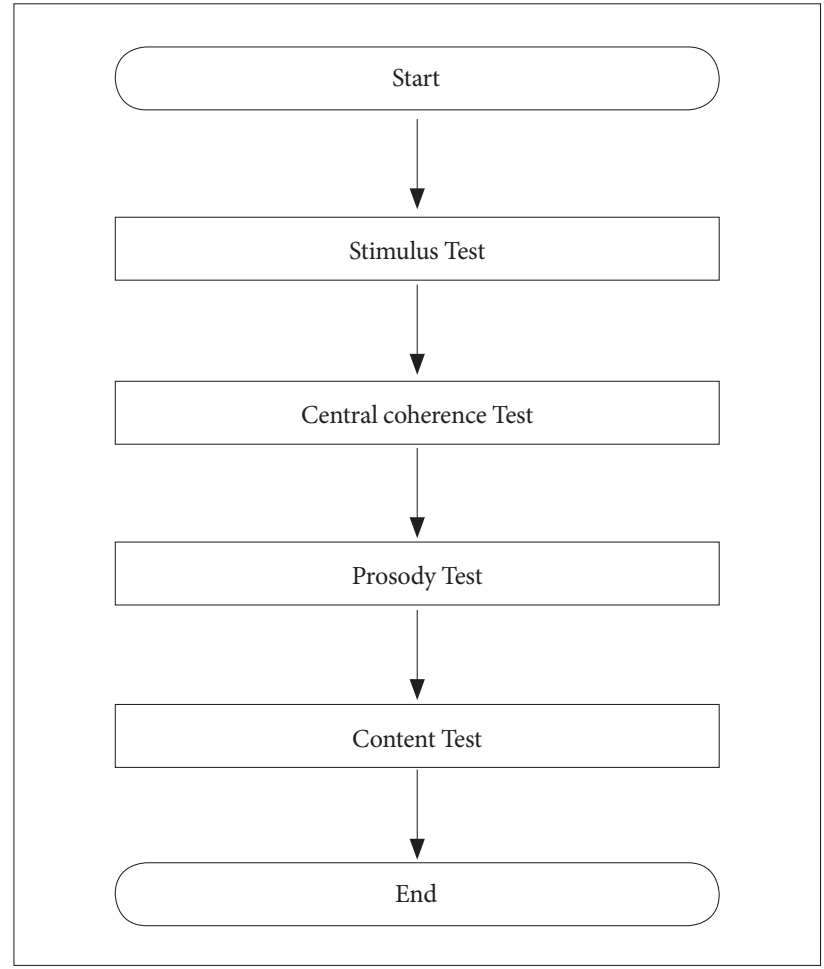

Figure 2. Flow chart on S-D program. S-D program: StimulusDiscrimination program.

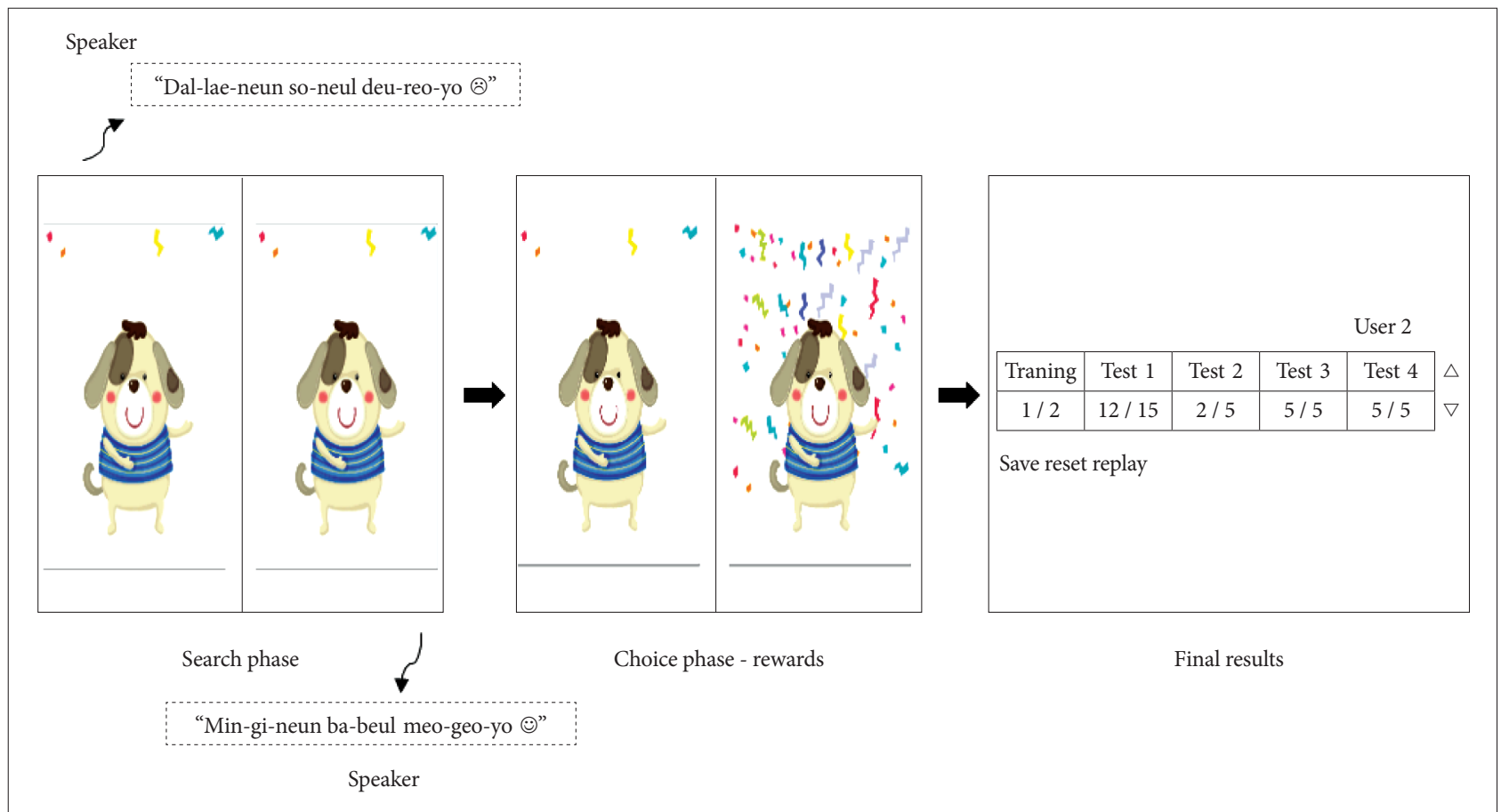

Figure 3. Example of the laptop's Liquid Crystal Display screen on S-D program. S-D program: Stimulus-Discrimination program. 
Table 2. Descriptive statistics on Stimulus Test

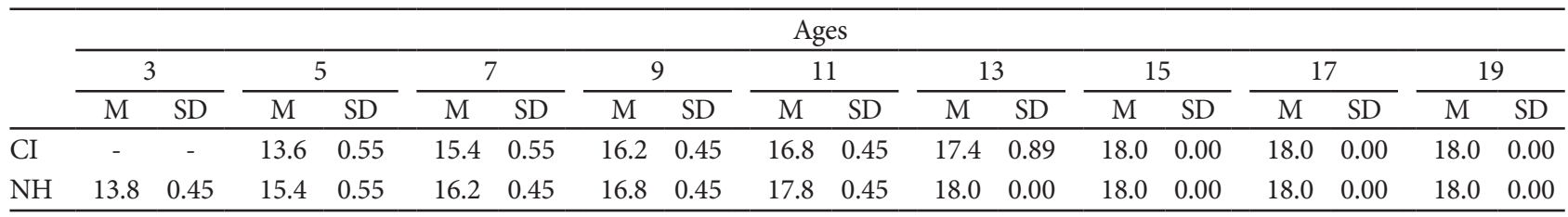

CI: cochlear implant, $\mathrm{NH}$ : normal hearing, M: mean, SD: standard deviation

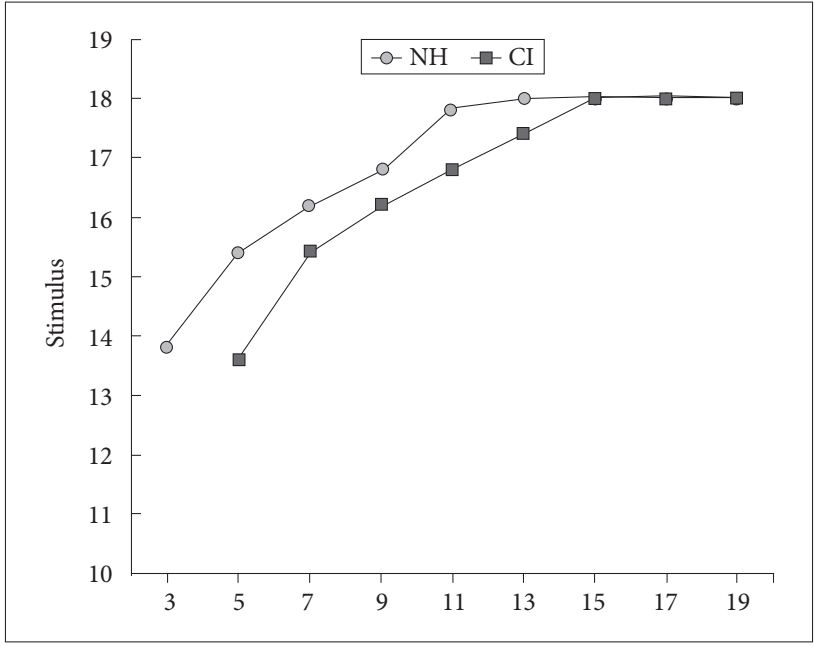

Figure 4. Double line graph of performance on Stimulus Test. NH: normal hearing, $\mathrm{Cl}$ : cochlear implant.

계와 진행 절차를 나타낸 것이다. 자극인지 테스트에서는 $\mathrm{S}+$ 와 $\mathrm{S}-$ 를 제시하고, 중앙통합능력 테스트에서는 $\mathrm{S}+$ 와 $\mathrm{S}-$ 의 운율과 내용을 재조합한 S1과 S2를 대조하여 제시하였다. 운율인지 테 스트와 내용인지 테스트에서는 S+와 함께 각각 $\mathrm{S} 1, \mathrm{~S} 2$ 를 제시 하였다. 첫 번째 자극인지 테스트에서 대상자는 S+를 선택하면 강화를 받는 과정을 통해 정반응의 기준이 되는 $\mathrm{S}+$ 의 운율 및 내용 특성을 익히게 된다. 이를 기반으로 다음에 이어지는 테 스트들에서 보다 구체적인 수행 성과를 구한다. 특별히 중앙통 합능력 테스트에서는 정반응이 아닌 운율 및 내용선호도를 측 정한다. 각 테스트에서 제시된 과제의 목록은 Appendix에 첨 부하였다.

\section{분석방법}

본 실험에서 수집되는 자료는 대상자별로 각 테스트에서 집 계된 수행점수 결과이다. 수행점수는 각 과제당 1점으로 계산 하여 S-D program에서 자동집계된다.

한편 집단 간 중앙통합능력을 알아보기 위해, 선행연구인 $\mathrm{Bae}(2001)$, Park \& Kim(2014) 등을 참고하여 본 연구의 목적 에 맞도록 중앙통합능력 계산법을 다음과 같이 응용하였다. 중 앙통합능력 테스트에서는 운율이나 내용 중 어느 쪽으로도 편 중되지 않은 확률이 0.5 라는 사실에 착안하여 대표값으로 활
Table 3. Independent $t$-test on Stimulus Test between $\mathrm{Cl}$ and $\mathrm{NH}$

\begin{tabular}{lcccc}
\hline & $\mathrm{M}$ & $\mathrm{SD}$ & $t$ & $p$ \\
\hline $\mathrm{CI}$ & 16.7 & 1.54 & 0.655 & 0.514 \\
$\mathrm{NH}$ & 16.9 & 1.47 & & \\
\hline
\end{tabular}

CI: cochlear implant, NH: normal hearing, M: mean, SD: standard deviation

Table 4. ANOVA on Stimulus Test between $\mathrm{Cl}$ and $\mathrm{NH}$

\begin{tabular}{lcclcc}
\hline & \multicolumn{2}{c}{ Cross-aged } & & \multicolumn{2}{c}{ Group $\times$ age interaction } \\
\cline { 2 - 3 } \cline { 5 - 6 } & $\mathrm{F}$ & $p$ & & $\mathrm{~F}$ & $p$ \\
\hline $\mathrm{CI}$ & 54.333 & 0.000 & & 5.695 & 0.000 \\
$\mathrm{NH}$ & 92.091 & 0.000 & & & \\
\hline
\end{tabular}

CI: cochlear implant, $\mathrm{NH}$ : normal hearing

용하였다. 즉 중앙통합능력이 발휘되지 않은 평균값인 0.5 를 대 표값으로 하여 운율선호도(또는 내용선호도)와의 편차를 구하 여 분석하였다. 본 연구에서는 운율선호도를 기준으로 중앙통 합능력을 아래 수식에 따라 구하였다. 운율선호도를 기준으로 계산하므로, 운율중앙통합능력은 양수(+)로 내용중앙통합능력 은 음수(-)로 결과값이 나타난다. 분석의 편리를 위해, 편차의 배수를 구하여 보편적인 단위인 백분율로 나타내었다. 대상자 별 중앙통합능력은 연령별 및 집단 내 중앙통합능력으로 환산 하여 집단 간 중앙통합능력의 차이를 분석하였다.

$$
\begin{aligned}
\text { 중앙통합능력 }(\mathrm{CC}) & =\text { 운율 또는 내용선호도 }{ }^{1)} \\
& =\text { 선호도가 } 0 \text { 인 확률 } 0.5 \text { 와의 편차 } \\
& =(\text { 운율선호도 }-0.5) \times 2
\end{aligned}
$$

모든 자료의 통계 처리는 SPSS(v. 22.0; SPSS Inc., Chicago, $\mathrm{IL}, \mathrm{USA}$ )를 사용하였다. 집단과 연령 상호작용의 차이는 이원 배치 분산분석(two-way ANOVA)을, 사후분석으로 Scheffe 검정을 실시하였다. 집단 및 연령 간 차이 분석은 각각 독립표 본 $t$ 검정, 일원배치 분산분석(one-way ANOVA)을 실시하여 알아보았다.

1) 운율과 내용 중 어느 하나를 선택한 백분율로 표시된다. S1, S2 두 문 장 중 $\mathrm{S} 1$ 을 선택하면 내용을, $\mathrm{S} 2$ 를 선택하면 운율을 선호한 것이다. 예를 들어 6세트 중 S1을 4번 선택했으면 그 아동의 운율/내용선호도 는 각각 $0.33 / 0.67$ 이다. 


\section{RESULTS}

\section{운율과 내용 조합 자극에 대한 자극 인지 능력의 차이}

운율과 내용이 조합된 자극을 제시하였을 때 자극 인지 능력 에 차이를 보이는지 알아보기 위해, $\mathrm{S}+($ 민기는 밥을 먹어요(-)) 와 S-(달래는 손을 들어용) 를 제시하여 S+를 선택하는 비율 을 조사하기 위한 자극인지 테스트를 실시하였다.

기술통계 결과, 전체 수행점수에서 와우아동이 16.7점, 건청 아동이 16.9점으로 건청아동이 와우아동보다 약간 높게 나타 났다. 이러한 차이가 집단 및 연령 간에 통계적으로 유의한지 알아보기 위해 독립표본 $t$ 검정 및 일원배치 분산분석을 실시한 결과, 우선 자극 인지 능력의 집단 간 차이는 $t=0.655, p>0.05$ 로 통계적으로 유의하지 않았다. 그러나 자극 인지 능력의 연령 간 차이에서는 와우아동 $(\mathrm{F}=54.333, p<0.001)$, 건청아동 $(\mathrm{F}=$ $92.091, p<0.001)$ 모두 연령에 따른 수행점수의 차이가 통계적 으로 유의하게 높았다. 연령 간 Scheffe 검정에서 와우아동 및 건청아동은 각각 5 세, 3 세에서 모든 연령과의 차이가 0.05 수준 에서 유의하였다. 또 자극인지 테스트에서 이원배치 분산분석 결과, 와우아동과 건청아동의 집단 및 연령 간 상호작용도 $\mathrm{F}=$ $5.695, p<0.001$ 로 통계적으로 유의하였다(Table 2-4).

자극인지 테스트의 집단 및 연령 간 수행 그래프는 Figure 4
에서 제시하였다.

\section{운율 및 내용 인지 능력의 차이}

\section{운율 인지 능력}

운율 인지 능력을 알아보기 위해 $\mathrm{S}+($ 민기는 밥을 먹어요(-)) 와 S1(민기는 밥을 먹어요으)를 제시하여 운율인지 테스트를 실 시하였다.

기술통계 결과, 전체 수행점수에서 와우아동이 5.0점, 건청 아동이 5.4점으로 건청아동이 와우아동보다 높게 나타났다. 이 러한 차이가 집단 및 연령 간에 통계적으로 유의한지 알아보기 위해 독립표본 $t$ 검정 및 일원배치 분산분석을 실시한 결과, 운 율 인지 능력의 집단 간 차이는 $t=1.408, p>0.05$ 로 통계적으 로 유의하지 않았다. 그러나 운율 인지 능력의 연령 간 차이에 서는 와우아동 $(\mathrm{F}=4.624, p<0.01)$, 건청아동 $(\mathrm{F}=5.766 p<$ 0.001) 모두 연령에 따른 수행점수의 차이가 통계적으로 유의 하게 높았다. 연령 간 Scheffe 검정에서 와우아동 및 건청아동 은 모든 연령에서 차이가 0.05 수준에서 유의하지 않았다. 한편 운율인지 테스트에서 이원배치 분산분석 결과, 와우아동과 건 청아동의 집단 및 연령 간 상호작용은 $\mathrm{F}=0.764, p>0.05$ 로 통계적으로 유의하지 않았다(Table 5-7).

Table 5. Descriptive statistics on Prosody Test

\begin{tabular}{|c|c|c|c|c|c|c|c|c|c|c|c|c|c|c|c|c|c|c|}
\hline & \multicolumn{18}{|c|}{ Ages } \\
\hline & \multicolumn{2}{|c|}{3} & \multicolumn{2}{|c|}{5} & \multicolumn{2}{|c|}{7} & \multicolumn{2}{|c|}{9} & \multicolumn{2}{|c|}{11} & \multicolumn{2}{|c|}{13} & \multicolumn{2}{|c|}{15} & \multicolumn{2}{|c|}{17} & \multicolumn{2}{|c|}{19} \\
\hline & M & SD & M & SD & M & SD & M & SD & M & SD & M & $\mathrm{SD}$ & M & SD & $\mathrm{M}$ & SD & $\mathrm{M}$ & $\mathrm{SD}$ \\
\hline $\mathrm{CI}$ & - & - & 2.8 & 2.39 & 4.4 & 0.55 & 5.0 & 1.00 & 5.2 & 0.45 & 5.4 & 0.89 & 5.6 & 0.55 & 5.8 & 0.45 & 5.8 & 0.45 \\
\hline $\mathrm{NH}$ & 3.4 & 1.67 & 4.6 & 0.89 & 5.0 & 1.41 & 5.8 & 0.45 & 5.8 & 0.45 & 5.8 & 0.45 & 6.0 & 0.00 & 6.0 & 0.00 & 6.0 & 0.00 \\
\hline
\end{tabular}

CI: cochlear implant, NH: normal hearing, M: mean, SD: standard deviation

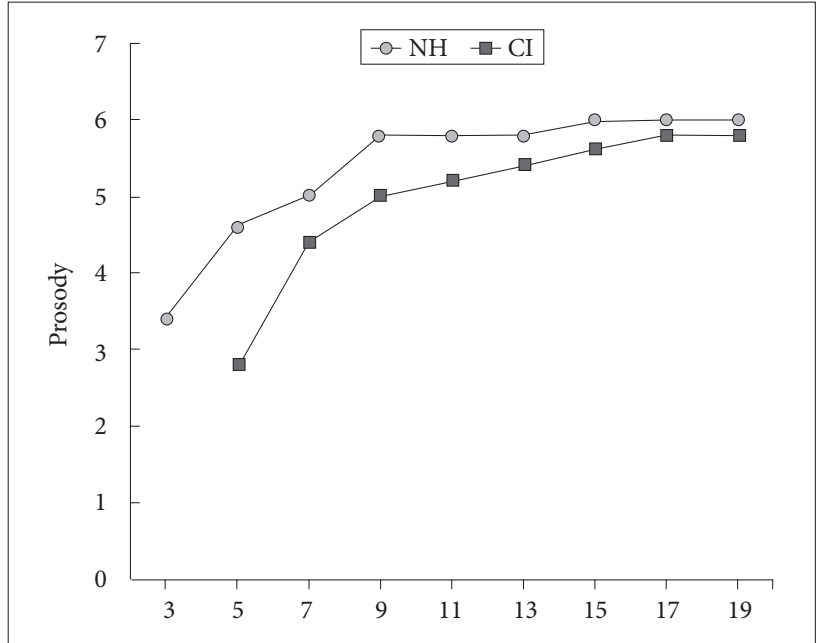

Figure 5. Double line graph of performance on Prosody Test. $\mathrm{NH}$ : normal hearing, $\mathrm{Cl}$ : cochlear implant.
Table 6. Independent $t$-test on Prosody Test between $\mathrm{Cl}$ and $\mathrm{NH}$

\begin{tabular}{lcccc}
\hline & $\mathrm{M}$ & $\mathrm{SD}$ & $t$ & $p$ \\
\hline $\mathrm{CI}$ & 5.0 & 1.34 & 1.408 & 0.163 \\
$\mathrm{NH}$ & 5.4 & 1.13 & &
\end{tabular}

CI: cochlear implant, NH: normal hearing, M: mean, SD: standard deviation

Table 7. ANOVA on Prosody Test between $\mathrm{Cl}$ and $\mathrm{NH}$

\begin{tabular}{lcclcc}
\hline & \multicolumn{2}{c}{ Cross-aged } & & \multicolumn{2}{c}{ Group $\times$ age interaction } \\
\cline { 2 - 3 } \cline { 5 - 6 } & $\mathrm{F}$ & $p$ & & $\mathrm{~F}$ & $p$ \\
\hline $\mathrm{CI}$ & 4.624 & 0.001 & & 0.764 & 0.619 \\
$\mathrm{NH}$ & 5.766 & 0.000 & & & \\
\hline
\end{tabular}

CI: cochlear implant, $\mathrm{NH}$ : normal hearing 
Table 8. Descriptive statistics on Content Test

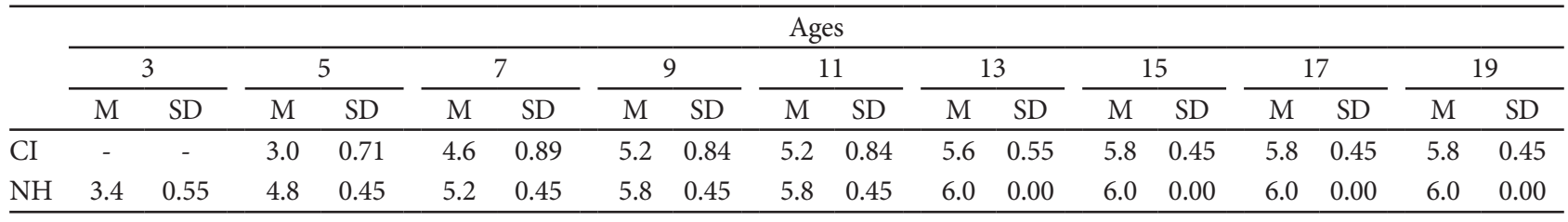

CI: cochlear implant, NH: normal hearing, M: mean, SD: standard deviation

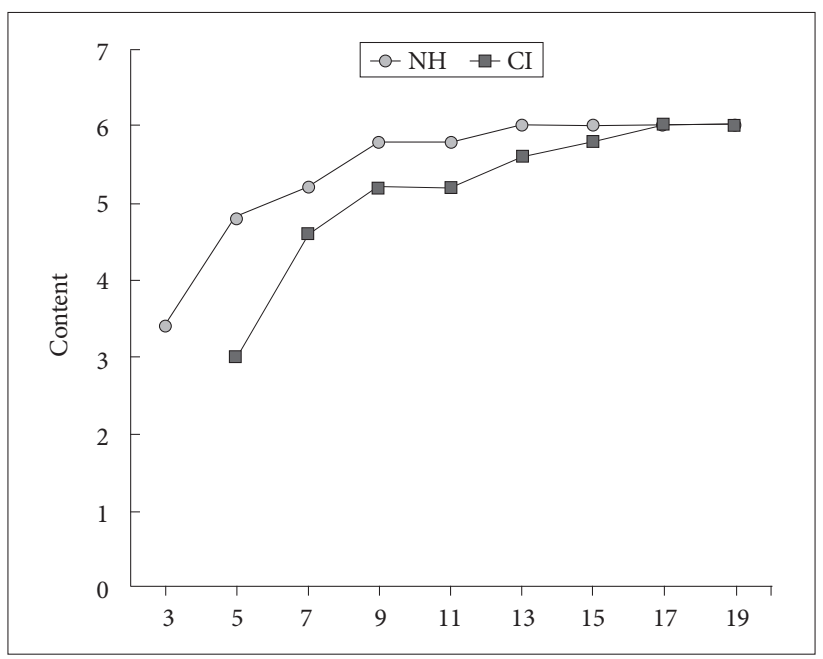

Figure 6. Double line graph of performance on Content Test. NH: normal hearing, $\mathrm{Cl}$ : cochlear implant.

운율인지 테스트의 집단 및 연령 간 수행 그래프는 Figure 5 에서 제시하였다.

\section{내용 인지 능력}

또한 내용 인지 능력을 알아보기 위해 S+(민기는 밥을 먹어 요(:))와 S2(달래는 손을 들어용)(를 제시하여 내용인지 테스 트를 실시하였다.

기술통계 결과, 전체 수행점수에서 와우아동이 5.1점, 건청아 동이 5.4점으로 건청아동이 와우아동보다 높게 나타났다. 이러 한 차이가 집단 및 연령 간에 통계적으로 유의한지 알아보기 위해 독립표본 $t$ 검정 및 일원배치 분산분석을 실시한 결과, 내 용 인지 능력의 집단 간 차이는 $t=1.484, p>0.05$ 로 통계적으 로 유의하지 않았다. 그러나 내용 인지 능력의 연령 간 차이에서 는 와우아동 $(\mathrm{F}=10.151, p<0.001)$, 건청아동 $(\mathrm{F}=31.409, p$ $<0.001)$ 모두 연령에 따른 수행점수의 차이가 통계적으로 유 의하게 높았다. 연령 간 Scheffe 검정에서 건청아동은 3세에서 모든 연령과의 차이가 0.05 수준에서 유의하였으나, 와우아동 은 모든 연령에서 유의한 결과가 없었다. 또한 내용인지 테스트 에서 이원배치 분산분석 결과, 와우아동과 건청아동의 집단 및 연령 간 상호작용도 $\mathrm{F}=2.525, p<0.05$ 로 통계적으로 유의한 차이가 나타났다(Table 8-10).

내용인지 테스트의 집단 및 연령 간 수행 그래프는 Figure 6
Table 9. Independent $t$-test on Content Test between $\mathrm{Cl}$ and $\mathrm{NH}$

\begin{tabular}{lcccc}
\hline & $\mathrm{M}$ & $\mathrm{SD}$ & $t$ & $p$ \\
\hline $\mathrm{CI}$ & 5.1 & 1.09 & 1.484 & 0.142 \\
$\mathrm{NH}$ & 5.4 & 0.89 & & \\
\hline
\end{tabular}

CI: cochlear implant, NH: normal hearing, M: mean, SD: standard deviation

Table 10. ANOVA on Content Test between $\mathrm{Cl}$ and $\mathrm{NH}$

\begin{tabular}{lccccc}
\hline & \multicolumn{2}{c}{ Cross-aged } & & \multicolumn{2}{c}{ Group $\times$ age interaction } \\
\cline { 2 - 3 } \cline { 5 - 6 } & $\mathrm{F}$ & $p$ & & $\mathrm{~F}$ & $p$ \\
\hline $\mathrm{CI}$ & 10.151 & 0.000 & & 2.525 & 0.023 \\
$\mathrm{NH}$ & 31.409 & 0.000 & & & \\
\hline
\end{tabular}

CI: cochlear implant, NH: normal hearing

에서 제시하였다.

\section{중앙통합능력의 차이}

집단 간 중앙통합능력의 차이를 알아보기 위해 $\mathrm{S} 1$ (민기는 밥 을 먹어요(*)과 S2(달래는 손을 들어요())를 제시하여 선호하 는 언어적 특징이 운율(S2)인지 내용(S1)인지를 조사하기 위한 중앙통합능력 테스트를 실시하였다. 선행연구인 Bae(2001), Park \& Kim(2014) 등을 참고하여 중앙통합능력 계산법을 응 용하였다. 중앙통합능력은 운율 또는 내용 중 어느 하나를 선호 하지 않은 확률인 0.5 를 대표값으로 하여 대표값 0.5 와 운율선 호도와의 편차를 구하여 분석하였다. 본 연구에서는 운율선호 도를 기준으로 중앙통합능력을 다음과 같이 구하였다.

$$
\begin{aligned}
\text { 중앙통합능력 }(\mathrm{CC}) & =\text { 운율 또는 내용선호도 } \\
& =\text { 선호도가 } 0 \text { 인 확률 } 0.5 \text { 와의 편차 } \\
& =(\text { 운율선호도 }-0.5) \times 2
\end{aligned}
$$

기술통계 결과, 중앙통합능력의 통합적인 분석에서 와우아 동은 0.23 , 건청아동은 0.43 으로 와우아동의 중앙통합능력이 건청아동보다 뚜렷하게 낮게 나타났다. 이러한 차이가 집단 간 에 통계적으로 유의한지 알아보기 위해 독립표본 $t$ 검정을 실시 한 결과, 중앙통합능력의 집단 간 차이는 $t=5.867, p<0.001$ 로 통계적으로도 유의하게 높았다. 그리고 일원배치 분산분석 결 과, 중앙통합능력의 연령 간 차이에서 와우아동은 연령에 따른 
Table 11. Descriptive statistics on Central coherence Test

\begin{tabular}{|c|c|c|c|c|c|c|c|c|c|c|c|c|c|c|c|c|c|c|}
\hline & \multicolumn{18}{|c|}{ Ages } \\
\hline & \multicolumn{2}{|c|}{3} & \multicolumn{2}{|c|}{5} & \multicolumn{2}{|c|}{7} & \multicolumn{2}{|c|}{9} & \multicolumn{2}{|c|}{11} & \multicolumn{2}{|c|}{13} & \multicolumn{2}{|c|}{15} & \multicolumn{2}{|c|}{17} & \multicolumn{2}{|c|}{19} \\
\hline & M & $\mathrm{CC}^{*}$ & M & CC & M & CC & M & CC & M & CC & M & CC & M & CC & $\mathrm{M}$ & CC & M & CC \\
\hline CI & - & - & 0.40 & -0.20 & 0.40 & -0.20 & 0.47 & -0.07 & 0.43 & -0.13 & 0.53 & 0.07 & 0.57 & 0.13 & 0.73 & 0.47 & 0.87 & 0.73 \\
\hline $\mathrm{NH}$ & 0.13 & -0.73 & 0.17 & -0.67 & 0.20 & -0.60 & 0.33 & -0.33 & 0.43 & -0.13 & 0.57 & 0.13 & 0.70 & 0.40 & 0.80 & 0.60 & 0.97 & 0.93 \\
\hline
\end{tabular}

${ }^{*}$ CC $(\%)=$ [Prosody Preference $\left.(\mathrm{M})-0.5\right] \times 2 \therefore$ positive number $(+)$ : Prosody CC, negative number (-): Content CC. CI: cochlear implant, $\mathrm{NH}$ : normal hearing, CC: Central coherence

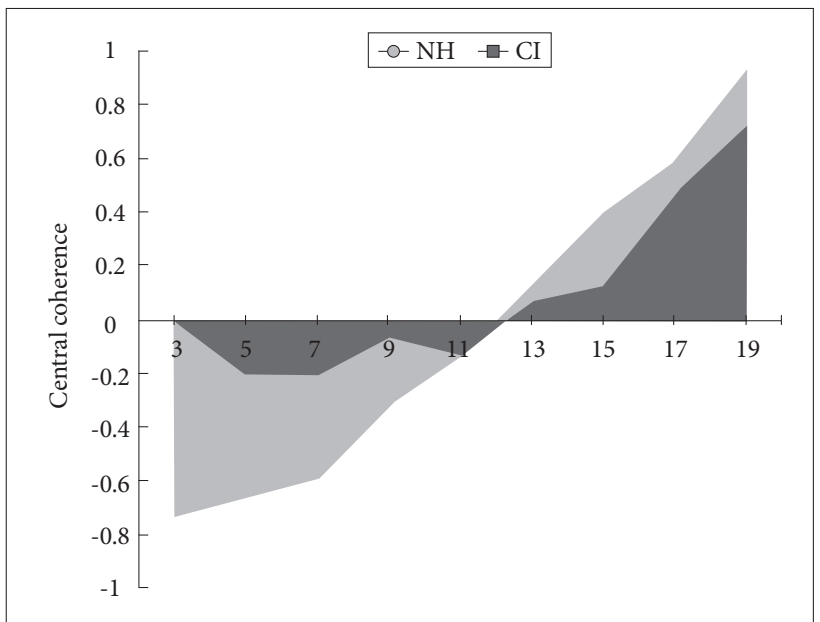

Figure 7. Double line graph of performance on Central coherence Test. $\mathrm{NH}$ : normal hearing, $\mathrm{Cl}$ : cochlear implant.

수행점수의 차이가 높았으나 $(\mathrm{F}=5.807, p<0.001)$, 건청아동은 연령 간 차이가 통계적으로 유의하지 않았다 $(\mathrm{F}=1.700, p>$ 0.05). 연령 간 Scheffe 검정에서 와우아동은 $7,9,11,15$ 세에서 일부 연령과의 차이가 0.05 수준에서 유의하였으나, 건청아동 은 모든 연령에서 유의한 결과가 없었다. 또한 중앙통합능력 테 스트에서 이원배치 분산분석 결과, 와우아동과 건청아동의 집 단 및 연령 간 상호작용도 $\mathrm{F}=3.097, p<0.01$ 로 통계적으로 유의한 차이가 나타났다(Table 11-13).

중앙통합능력 테스트의 집단 및 연령 간 수행 그래프는 Figure 7에서 제시하였다.

\section{DISCUSSIONS}

본 연구에서는 자극-인지 프로그램으로 고안된 S-D program을 활용하여 운율 및 내용이 조합된 자극을 제시하였을 때 인공와우 착용 아동의 청각 인지 특성을 알아보고 연령에 따라 중앙통합능력이 어떻게 변화하는지 살펴보고자 하였다.

첫째, 운율과 내용이 조합된 자극을 제시하여 자극 인지 능 력을 알아본 결과, 각 집단에서는 연령 간 차이를 나타내었고 (와우아동: $p<0.001$, 건청아동: $p<0.001$ ), 집단 및 연령 간 상호작용에서도 차이를 나타내었다 $(p<0.001)$. 반면 자극 인 지에서 집단 간 차이는 나타나지 않았다. 우선 자극 인지 능력
Table 12. Independent $t$-test on Central coherence Test between $\mathrm{Cl}$ and $\mathrm{NH}$

\begin{tabular}{lcccc}
\hline & $\mathrm{M}^{*}$ & $\mathrm{SD}$ & $t$ & $p$ \\
\hline $\mathrm{CI}$ & 0.23 & 0.19 & 5.867 & 0.000 \\
$\mathrm{NH}$ & 0.43 & 0.13 & & \\
\hline
\end{tabular}

*mean of Central Coherence in each group. CC $(\%)=[$ Prosody Preference $(\mathrm{M})-0.5] \therefore 0 \leq \mathrm{CC} \leq 0.5$. CI: cochlear implant, NH: normal hearing, CC: Central coherence

Table 13. ANOVA on Central coherence Test between $\mathrm{Cl}$ and $\mathrm{NH}$

\begin{tabular}{lccccc}
\hline & \multicolumn{2}{c}{ Cross-aged } & & \multicolumn{2}{c}{ Group $\times$ age interaction } \\
\cline { 2 - 3 } \cline { 5 - 6 } & $\mathrm{F}$ & $p$ & & $\mathrm{~F}$ & $p$ \\
\hline $\mathrm{CI}$ & 5.807 & 0.000 & & 3.097 & 0.007 \\
$\mathrm{NH}$ & 1.700 & 0.132 & & & \\
\hline
\end{tabular}

CI: cochlear implant, $\mathrm{NH}$ : normal hearing

에서 와우아동이 건청아동의 경우처럼 연령 간 차이를 보여주 었는데, 이러한 결과는 와우아동의 자극 인지 능력이 착용기간 이 더해가면서 발달하고 있음을 보여주는 증거이다. 연령 간 Scheffe 검정에서 와우아동 및 건청아동은 각각 5 세, 3 세에서 모든 연령과의 차이가 0.05 수준에서 유의하였다. 이는 본 연구 대상자의 인공와우 착용기간이 3년 이상이므로 Huh et al. (2007)에 미루어 보면, 인공와우 착용 후 12 개월 이전에 말 인 지 능력이 유의하게 향상되는 효과가 이미 충분히 반영되어 건 청아동의 연령 간 발달 패턴과 유사해진 것이라 볼 수 있다. 또 한 집단 및 연령 상호 간에도 자극 인지 능력에서 통계적으로 유의한 차이가 있었는데 이는 연령 간 차이와 관련이 있다고 볼 수 있다. 와우아동과 건청아동의 집단 간 차이는 유의하지 않았는데 이는 와우아동이 건청아동과 같은 수준의 인지 능력 을 보여주는 것이다. 전반적으로 두 집단 간 차이가 없으나. 낮 은 연령에서는 와우아동과 건청아동의 차이가 크고 높은 연령 에서는 차이가 적거나 없었다.

둘째, 운율 및 내용의 인지 능력을 알아본 결과, 운율과 내용 인지 모두에서 각 집단은 연령 간 차이를 나타내었고, 집단 간 차이는 없었다. 내용 인지에서는 집단 및 연령 간 상호작용의 차이가 있었으나 운율 인지에서는 차이가 나타나지 않았다. 먼 저 운율 인지 능력에서 와우아동은 건청아동의 경우처럼 연령 간 차이를 보여주었다(와우아동: $p<0.01$, 건청아동: $p<$ 
0.001). 그러나 운율 인지 능력의 집단 및 연령 간 상호작용은 차 이가 없었다 $(p>0.05)$. 다음 내용 인지 능력에서도 와우아동 은 건청아동의 경우처럼 연령 간 차이를 보여주었다(와우아동: $p<0.001$, 건청아동: $p<0.001)$. 또 내용 인지 능력에서는 집 단 및 연령 간 상호작용의 차이가 나타났다 $(p<0.05)$. 운율 및 내용 인지에서 이러한 결과는, 인공와우 착용기간에 따라 운율 및 내용 인지 능력이 향상된다는 선행연구들의 결과와 일치한 다(Govaerts et al., 2002; Huh et al., 2007; Robinson, 1998). 한편 본 연구의 테스트 중 유일하게 운율 인지 능력에서만 집 단 및 연령 상호작용 간의 차이가 유의하지 않은 것은, Scheffe 검정에서 연령 간 차이가 없는 결과로 볼 때 착용기간에 따라 운율 능력이 향상되지만 어느 정도 한계가 있음을 보여준다. 와우아동의 운율 향상은 Channel interaction 현상으로 인해 Fine structure가 전달되지 않는 인공와우의 시스템적인 한계 로 인해 제약을 받는다(Jin, 2006). 반면 내용 인지 능력에서는 집단 및 연령 상호 간의 차이가 유의하였는데, 이러한 결과는 인공와우 착용이 내용 인지 능력의 향상에 있어서 운율보다 더 괄목할만한 기여도를 보여주는 것이다. Figure 5 와 6에서 와우 아동은 17 세와 19 세에서 운율 인지는 건청아동에 미치지 못하 나 내용 인지는 동일한 결과를 나타내었다. 본 연구에서는 인공 와우 착용의 효과가 운율과 내용 모두에 기여하지만 운율 인지 보다 내용 인지 능력의 발달에 보다 분명하게 통계적으로 드러 나고 있다. 이것은 전기한 인공와우의 기술적인 한계와 더불어, 언어발달 단계상 보편적으로 구문 및 의미적 요소(내용)의 발 달이 화용적 요소(운율)보다 선행하는 것과도 관련이 있다고 여겨진다(Kuder, 2007, 2010).

마지막으로, 중앙통합능력의 차이를 알아본 결과, 와우아동 과 건청아동은 중앙통합능력에서 집단 간 차이가 뚜렷이 나타 났다 $(p<0.001)$. 또 와우아동은 건청아동과 달리 연령 간 차 이도 드러내었다 $(p<0.001)$. 두 집단은 집단 및 연령 간 상호작 용에 있어서도 차이를 보였다 $(p<0.01)$. 먼저 중앙통합능력의 집단 간 차이가 분명하였는데, 이는 중앙통합능력을 발휘하여 운율이나 내용 중 어느 하나를 선호한 건청아동에 비해 와우아 동은 운율이나 내용 중 어느 하나를 선호하여 반응하지 않음으 로 상대적으로 중앙통합능력이 약함을 보여주는 것이다. 또 집 단 및 연령 간 상호작용의 차이는, 5 세로부터 11 세에 이르는 기 울기의 차이에서 비롯됨을 Figure 7의 그래프가 보여주고 있다. Figure 7에서 확인할 수 있듯이 모든 연령에서 와우아동은 건 청아동보다 중앙통합능력이 낮게 나타나는데, 특히 5세로부터 11 세에 이르는 구간은 내용중앙통합능력이 뚜렷한 건청아동과 비교하면 와우아동의 독특한 중앙통합능력을 확연히 드러내고 있다. 즉 와우아동의 중앙통합능력은 5 세로부터 11세까지 변화 가 거의 없고 0 에 근접해 있다. 이후 11 세가 지나면서 와우아동
도 중앙통합능력의 발달 양상이 건청아동과 유사해지는데, 이 를 통해 인공와우 착용 후 중앙통합능력이 향상되기까지 상당 한 기간의 중재가 필요함을 예측할 수 있다. 이러한 패턴은 와 우아동의 연령 간 차이에서도 볼 수 있는데, 연령 간 Scheffe 검 정에서 와우아동은 $7,9,11,15$ 세에서 일부 연령과의 차이가 0.05 수준에서 유의하였다. 한편 Figure 7에서 건청아동이 나 이가 들수록 내용중앙통합능력에서 운율중앙통합능력으로 발 달하는 것은 건청아동의 언어발달 특성 때문이라 여겨진다. 보 통 10세 이후에 건청아동의 운율선호도가 높아진다고 알려져 있는데(Friend \& Bryant, 2000; Morton \& Trehub, 2001), 본 연구에서도 11 세와 13 세 사이에서 중앙통합능력이 내용에서 운율로 전환되는 것을 확인할 수 있다. 그 시기는 또한 와우아 동이 중앙통합능력을 출현시키고 건청아동과 정(+)의 상관관계 로 중앙통합능력을 발달하기 시작하는 시점임을 그래프에서 볼 수 있다.

앞선 자극/운율/내용인지 테스트의 결과에서 와우아동은 건 청아동과 유사한 수준의 인지 능력이 있음을 확인하였다. 인지 능력에 결함이 없음에도 불구하고 와우아동이 약한 중앙통합 능력을 보이는 것은, Parallel stimulation을 제한하는 인공와우 의 기술적 한계 때문이다. 운율, 내용이 각각 개별적인 자극으 로 제시되는 과제에는 처리 과정에 어려움이 없었지만 운율과 내용이 결합된 자극이 주어지면 Channel interaction이 동시적 인 신호의 처리를 저해하여 인지와 선택을 어렵게 하는 것이다. 이러한 인공와우 시스템의 한계에도 어느 시점에서 중앙통합능 력이 출현되는데, 인공와우의 착용기간과 청능 훈련이 청각 정 보의 활용 능력을 향상한 결과로 보여진다. 바로 여기에서 청각 장애에 대한 언어 중재의 가능성이 기대와 기우로 갈라진다. 약 한 중앙통합능력은 지적장애를 가진 대상 집단에서 보편적으 로 나타나는 인지적 특성이지만, 지적 능력이 부족하지 않은 청 각장애에도 수반될 수 있음을 추정해 볼 수 있다. 그러나 인공 와우 착용은 Parallel stimulation에 한계가 있음에도 중앙통합 능력의 회복에 기여한다. 인공와우의 열악한 temporal 및 spectral resolution의 원인인 Channel interaction을 최소화하는 도 전이 실현될수록 청력의 향상 이면에 중앙통합능력을 회복시 켜 원활한 의사소통의 장에까지 이르게 하리라 기대하게 한다.

중심 단어 : 인공와우·운율·내용·중앙통합능력· S-D program.

\section{REFERENCES}

American Speech-Language-Hearing Association. (1993). Ad Hoc Committee on Service Delivery in the Schools. American Speech-LanguageHearing Association.

Bae, K. S. (2001). The central coherence and the theory of mind accounts of high-functioning autism (unpublished master's thesis). Ewha Uni- 
versity, Seoul.

Beak, S. Y. (2010). Acoustic Analysis on the Intonation Characteristics by Infants with Cochlear Implants (unpublished master's thesis). Dankook University, Yongin.

Bernardino, I., Mouga, S., Almeida, J., van Asselen, M., Oliveira, G., \& Castelo-Branco, M. (2012). A direct comparison of local-global integration in autism and other developmental disorders: implications for the central coherence hypothesis. PloS One, 7(6), e39351.

Brooks, P. J. \& Ploog, B. O. (2013). Attention to emotional tone of voice in speech perception in children with autism. Research in Autism Spectrum Disorders, 7(7), 845-857.

Friend, M. \& Bryant, J. B. (2000). A developmental lexical bias in the inter pretation of discrepant messages. Merill-Palmer Quaterly, 46(2), 342 369.

Frith, U. (1989). Autism: Explaining the enigma. Oxford: Basil Blackwell.

Govaerts, P. J., De Beukelaer, C., Daemers, K., De Ceulaer, G., Yperman, M., Somers, T., et al. (2002). Outcome of cochlear implantation at different ages from 0 to 6 years. Otology and Neurotology, 23(6), 885-890.

Grossman, R. B., Bemis, R. H., Plesa Skwerer, D., \& Tager-Flusberg, H. (2010). Lexical and affective prosody in children with high-functioning autism. Journal of Speech, Language, and Hearing Research, 53(3), 778-793.

Happé, F. \& Frith, U. (2006). The weak coherence account: Detail-focused cognitive style in autism spectrum disorders. Journal of Autism and Developmental Disorders, 36(1), 5-25.

Huh, M. J. (2010). Auditory perception Development for young children with hearing impaired in terms of CI use. The Journal of Special Children Education, 12(1), 67-80.

Huh, M. J., Choi, S. K., \& Lee, S. H. (2007). Longitudinal study of speech perception ability for profoundly deafened children with cochlear implant. Journal of Speech-Language and Hearing Disorders, 16(2), 77-87.

Jang, H. S. (2008). Proceedings from the 15th International Seminar \& 2008 Audiology Seminar on National Institute of Special Education \& Korean Academy of Audiology: Aural Rehabilitation for Children with Hearing Loss in Educational Settings (pp.93-113). Seoul: The K Arthall.

Jin, I. S. (2006). Recent Technology in MED-EL Cochlear Implant System. Audiology, 2(2), 119-125.

Kuder, S. J. (2010). Teaching students with language and communication disabilities (Kim, H. S., Trans.). Seoul: Sigma Press. (Original work published 2007).

Lanson, B. G., Green, J. E., Roland, J. T. Jr., Lalwani, A. K., Waltzman, S. B. (2007). Cochlear implantation in Children with CHARGE syndrome: Therapeutic decisions and outcomes. The Laryngoscope, 117(7), 12601266.
Lee, D. \& Choi, S. K. (2011). A comparative study on the perception of interval and rhythm by hearing impaired children who use cochlear implants and hearing aids. Journal of Speech and Hearing Disorders, 20(2), 125-148.

Lee, E. K. \& Seok, D. I. (2004). The effect on the improvement of stress through the prosody training for the cochlear implant children. Journal of Speech and Hearing Disorders, 13(3), 123-135.

Lenarz, T., Lesinski-Schiedat, A., von der Haar-Heise, S., Illg, A., Bertram, B., \& Battmer, R. D. (1999). Cochlear implantation in children under the age of two: The MHH experience with the CLARION cochlear implant. Medizinische Hochschule Hannover. The Annals of Otology, Rhinology and Laryngology. 177(Suppl.), 44-49.

May-Mederake, B., Kuehn, H., Vogel, A., Keilmann, A., Bohnert, A., Mueller, S., et al. (2010). Evaluation of auditory development in infants and toddlers who received cochlear implants under the age of 24 months with the LittlEARS) Auditory Questionnaire. International Journal of Pediatric Otorhinolaryngology, 74(10), 1149-1155.

Morton, J. B. \& Trehub, S. E. (2001). Children's understanding of emotion in speech. Child Development, 72(3), 834-843.

Park, G. N. \& Kim, W. S. (2014). Cognitive characteristics of prosody and sentences in low-functioning children with ASD. Journal of SpeechLanguage and Hearing Disorders, 23(3), 79-89.

Park, M. Y. \& Park, M. K. (2007). An analysis of emotional speech using distribution chart of F0. Korean Studies, 27, 233-254.

Ploog, B. O., Banerjee, S., \& Brooks, P. J. (2009). Attention to prosody (intonation) and content in children with autism and in typical children using spoken sentences in a computer game. Research in Autism Spectrum Disorders, 3(3), 743-758.

Robinson, K. (1998). Implications of developmental plasticity for the language acquisition of deaf children with cochlear implants. International Journal of Pediatric Otorhinolaryngology, 46(1-2), 71-80.

Scherer, K. R. (1986). Vocal affect expression: A review and a model for future research. Psychological Bulletin, 99(2), 143-165.

Seo, Y. O. (2010). The effects on the improvement of prosody disposition through the chant program for the cochlear implant children (unpublished master's thesis). Daegu University, Gyeongsan.

Välimaa, T. T., Määttä, T. K., Löppönen, H. J., \& Sorri, M. J. (2002). Phoneme recognition and confusions with multichannel cochlear implants: vowels. Journal of Speech, Language, and Hearing Research, 45(5), 1039-1054.

Yang, Y. J. (2013). Prosodic perception characteristics in children with cochlear implants (unpublished master's thesis). Dankook University, Yongin. 


\section{APPENDIX}

\section{A brief description of trial types in test}

\begin{tabular}{|c|c|c|c|}
\hline & Purpose & Trial sentence & Description \\
\hline $\begin{array}{l}\text { Stimulus Test } \\
\text { (rewards) }\end{array}$ & $\begin{array}{l}\text { Establish the experimental } \\
\text { comprehension and examine the } \\
\text { perception ability } \\
\text { of the participants. }\end{array}$ & $\begin{array}{l}\text { S+: Min-gi-neun ba-beul } \\
\text { meo-geo-yo }: ; \\
\text { S-: Dal-lae-neun so-neul } \\
\text { deu-reo-yo }:\end{array}$ & $\begin{array}{l}\text { It consists of } 18 \text { tasks. If participants select S+, } \\
\text { it is automatically counted } 1 \text { point and } \\
\text { presented visual rewards. Two auditory } \\
\text { stimulus are played on the right and } \\
\text { left pictures at random by each task. The } \\
\text { one-time only test is carried out. }\end{array}$ \\
\hline $\begin{array}{l}\text { Central coherence Test } \\
\text { (no rewards) }\end{array}$ & $\begin{array}{l}\text { Investigate of preference for } \\
\text { prosody or content to evaluate } \\
\text { central coherenece. Confirms } \\
\text { whether the information that } \\
\text { the distinctive feature } \\
\text { of reinforcement for the } S+\text {. }\end{array}$ & $\begin{array}{l}\text { S1: Min-gi-neun ba-beul } \\
\text { meo-geo-yo }: \\
\text { S2: Dal-lae-neun so-neul } \\
\text { deu-reo-yo }: ;\end{array}$ & $\begin{array}{l}\text { It consists of } 6 \text { tasks. If participants select } S 1 \text {, } \\
\text { it is automatically counted } 1 \text { point. The total } \\
\text { score indicates a score prefer to prosody. } \\
\text { Two auditory stimulus are played at } \\
\text { random by each task and do not involve } \\
\text { visual rewards. The one-time only test is } \\
\text { carried out. }\end{array}$ \\
\hline $\begin{array}{l}\text { Prosody Test } \\
\text { (no rewards) }\end{array}$ & $\begin{array}{l}\text { Check out the prosody } \\
\text { perception ability. That is, to } \\
\text { assess the perception of prosody } \\
\text { based on the prosodic features } \\
\text { of S+. }\end{array}$ & $\begin{array}{l}\text { S+: Min-gi-neun ba-beul } \\
\text { meo-geo-yo }:- \\
\text { S1: Min-gi-neun ba-beul } \\
\text { meo-geo-yo : }\end{array}$ & $\begin{array}{l}\text { It consists of } 6 \text { tasks. If participants select } S+\text {, } \\
\text { it is automatically counted } 1 \text { point. The total } \\
\text { score indicates a prosody score. Two } \\
\text { auditory stimulus are played at random by } \\
\text { each task and do not involve visual rewards. } \\
\text { The one-time only test is carried out. }\end{array}$ \\
\hline $\begin{array}{l}\text { Content Test } \\
\text { (no rewards) }\end{array}$ & $\begin{array}{l}\text { Check out the content } \\
\text { perception ability. That is, to } \\
\text { assess the perception of content } \\
\text { based on the content features of } \\
\text { S+. }\end{array}$ & $\begin{array}{l}\text { S+: Min-gi-neun ba-beul } \\
\text { meo-geo-yo }: ; \\
\text { S2: Dal-lae-neun so-neul } \\
\text { deu-reo-yo }:\end{array}$ & $\begin{array}{l}\text { It consists of } 6 \text { tasks. If participants select } \mathrm{S}+\text {, } \\
\text { it is automatically counted } 1 \text { point. The total } \\
\text { score indicates a content score. Two } \\
\text { auditory stimulus are played at random by } \\
\text { each task and do not involve visual rewards. } \\
\text { The one-time only test is carried out. }\end{array}$ \\
\hline
\end{tabular}

;:) enthusiastic prosody, :: grouchy prosody 